\title{
Frequency Domain Feature Extraction Investigation to Increase the Accuracy of an Intelligent Nondestructive System for Volume Fraction and Regime Determination of Gas-Water-Oil Three-Phase Flows
}

\author{
Osman Taylan ${ }^{1}$ (D), Mohammad Amir Sattari ${ }^{2}$, Imene Elhachfi Essoussi ${ }^{1}$ and Ehsan Nazemi $^{3, *(D)}$ \\ 1 Department of Industrial Engineering, Faculty of Engineering, King Abdulaziz University, P.O. Box 80204, \\ Jeddah 21589, Saudi Arabia; otaylan@kau.edu.sa (O.T.); iessoussi@kau.edu.sa (I.E.E.) \\ 2 Friedrich-Schiller-University Jena, Max-Wien-Platz 1, 07743 Jena, Germany; mohamadamir.satari@gmail.com \\ 3 Imec-Vision Lab, Department of Physics, University of Antwerp, 2610 Antwerp, Belgium \\ * Correspondence: ehsan.nazemi@uantwerpen.be
}

\section{check for}

updates

Citation: Taylan, O.; Sattari, M.A.; Elhachfi Essoussi, I.; Nazemi, E. Frequency Domain Feature Extraction Investigation to Increase the Accuracy of an Intelligent Nondestructive System for Volume Fraction and Regime Determination of Gas-WaterOil Three-Phase Flows. Mathematics 2021, 9, 2091. https://doi.org/ $10.3390 /$ math 9172091

Academic Editor: Mario Versaci

Received: 13 July 2021

Accepted: 27 August 2021

Published: 29 August 2021

Publisher's Note: MDPI stays neutral with regard to jurisdictional claims in published maps and institutional affiliations.

Copyright: (c) 2021 by the authors. Licensee MDPI, Basel, Switzerland. This article is an open access article distributed under the terms and conditions of the Creative Commons Attribution (CC BY) license (https:/ / creativecommons.org/licenses/by/ $4.0 /)$.

\begin{abstract}
In this research, a methodology consisting of an X-ray tube, one Pyrex-glass pipe, and two $\mathrm{NaI}$ detectors was investigated to determine the type of flow regimes and volume fractions of gas-oil-water three-phase flows. Three prevalent flow patterns-namely annular, stratified, and homogenous - in various volume percentages - $10 \%$ to $80 \%$ with the step of $10 \%$-were simulated by MCNP-X code. After simulating all the states and collecting the signals, the Fast Fourier Transform (FFT) was used to convert the data to the frequency domain. The first and second dominant frequency amplitudes were extracted to be used as the inputs of neural networks. Three Radial Basis Function Neural Networks (RBFNN) were trained for determining the type of flow regimes and predicting gas and water volume fractions. The correct detection of all flow regimes and the determination of volume percentages with a Mean Relative Error (MRE) of less than 2.02\% shows that the use of frequency characteristics in determining these important parameters can be very effective. Although X-ray radiation-based two-phase flowmeters have a lot of advantages over the radioisotope-based ones, they suffer from lower measurement accuracy. One reason might be that the X-ray multi-energy spectrum recorded in the detector has been analyzed in a simple way. It is worth mentioning that the $\mathrm{X}$-ray sources generate multi-energy photons despite radioisotopes that generate single energy photons, therefore data analyzing of radioisotope sources would be easier than X-ray ones. As mentioned, one of the problems researchers have encountered is the lower measurement accuracy of the X-ray, radiation-based three-phase flowmeters. The aim of the present work is to resolve this problem by improving the precision of the $\mathrm{X}$-ray, radiation-based three-phase flowmeter using artificial neural network (ANN) and feature extraction techniques.
\end{abstract}

Keywords: volume fraction; RBF neural network; feature extraction; frequency domain

\section{Introduction}

One of the most vital challenges in the oil, gas, and petrochemical industry is determining the volume percentages and diagnosing the type of flow regimes passing through the oil transmission lines. Hence, a lot of research has been done in this regard. There are many non-invasive methods to determine these parameters, such as photon attenuation methods, capacitive tomography, resistance tomography, X-rays, and so on. In recent years, much research has been done to detect these parameters using photon attenuation techniques [1-14]. The researchers in reference [1] studied three types of flow regimes with the names of stratified, homogeneous, and annular in different volume percentages using MCNP code. In this study, two radioisotope sources and three NaI detectors were used to determine the volume percentages and the type of flow regimes. An artificial neural network was designed to detect the type of flow regimes. Three separate networks 
were designed to determine the volume percentages of oil-water-gas three-phase flow. In another study, researchers proposed a new structure for measuring volume percentages in a stratified regime. This structure used an NaI detector next to a cesium-137 source to record the backscattered gamma radiation's energy spectrum. They also used the MLP neural network to determine volume percentages with an error of less than $6.47 \%$ [2].

In recent years, researchers have paid special attention to feature extraction from signals received from detectors. For example, Sattari et al. have researched the time domain characteristics to introduce the most appropriate ones [3]. In this study, a measurement system consisting of a cesium-137 source and two NaI detectors and a Pyrex-glass was implemented to determine the volume percentages and the type of flow regimes. After collecting the data, some features in the time domain were extracted to better interpret the data, and finally they were able to correctly identify the type of flow regimes using the MLP neural network and predict the volume percentages with high accuracy. In another study [4], researchers used time domain characteristics and the GMDH neural network to determine the volume percentages and type of flow regimes using only one detector. Roshani et al. used the dual energy method to study three-phase flows. Their detection system consisted of two $241 \mathrm{Am}$ and 137 Cs sources, and two NaI detectors. They used the characteristics of recorded counts of $241 \mathrm{Am}$ and $137 \mathrm{Cs}$ in two detectors to train the neural network, and they were finally able to predict volume percentages with an MRE\% of less than 5.68\% [5]. Hanus et al. Presented several time [6] and frequency [7] domain characteristics to determine the type of flow regimes in two-phase flows, and finally identified the most effective characteristics for determining this parameter. In their next research, they tried to determine the type of flow regimes by using these characteristics and using various neural networks [8]. Hosseini et al. Used the FFT to convert recorded signals to the frequency domain and then time domain characteristics were extracted from the frequency domain signals. Using these characteristics, they were able to accurately detect all flow regimes and predict the volume percentages in two-phase flows with high accuracy [9].

Advantages such as the ability to adjust the emitted photons energy of the X-ray tube, high-intensity photons emission, the ability to turn it on and off-this advantage is very important for the health of people working with these devices-, and the ability to transport it easily and steadily. Its energy retention over time has led current researchers to use X-ray tubes instead of radioisotopes [15-18]. In [15], an X-ray densitometry system was introduced. In this study, an X-ray tube $(50 \mathrm{kV}, 1 \mathrm{~mA})$ and some linear detectors were applied for two-phase flow metering. In the research [16], an X-ray tube and one NaI detector were used. The annular and stratified flow patterns were simulated. Obtained accuracy of the proposed methodology showed the ability to use X-ray tubes and ANN to determine the characteristics of multiphase flows. In [17], a structure consisting of an X-ray tube and two detectors was implemented to determine the volume percentages and type of flow regimes in three-phase flows. In this study, characteristics of recorded photon energy spectra from the two detectors and the GMDH neural network were used to determine the mentioned parameters. All flow regimes were correctly detected except one case, and volume percentages with RMSE less than 3.1 were predicted. In Reference [18], a methodology was proposed for determining the volume percentages in three-phase flows by simulating two flow regimes of stratified and annular at different volume percentages. The proposed structure consists of an X-ray tube and a NaI detector. One hundred characteristics were extracted from the received data from the detector and were considered as the input of the GMDH neural network. Since the GMDH neural network has the ability to determine effective inputs to predict the target, this network was applied as a tool for feature selection. Finally, volume percentages were predicted with an MRE\% of less than $6.69 \%$.

The purpose of this study is to use X-ray tubes, feature extraction techniques in the frequency domain, and the RBF neural network to increase the accuracy in determining critical parameters such as volume fractions and the type of flow regimes in oil-gas-water three-phase flows. 


\section{Materials and Methods}

\subsection{Radiation-Based System}

In this research, a detection system consisting of an X-ray tube, a Pyrex-glass pipe, and two NaI detectors with dimensions of $2.54 \mathrm{~mm} \times 2.54 \mathrm{~mm}$ was simulated using the MCNP-X code. In this system, detectors were placed at a distance of $20 \mathrm{~cm}$ from the source, one of them was directly related to the source, and the other was at an angle of $15^{\circ}$ to the source. A Pyrex-glass has been used to simulate flow regimes at different volume percentages. The structure of the designed system is shown in Figure 1. The three common flow regimes, shown in Figure 2, were simulated in volume percentages from 10\% to $80 \%$ with a step of $10 \%$. Thirty-six various volume fractions were simulated for each flow pattern, which includes a total of 108 simulations.

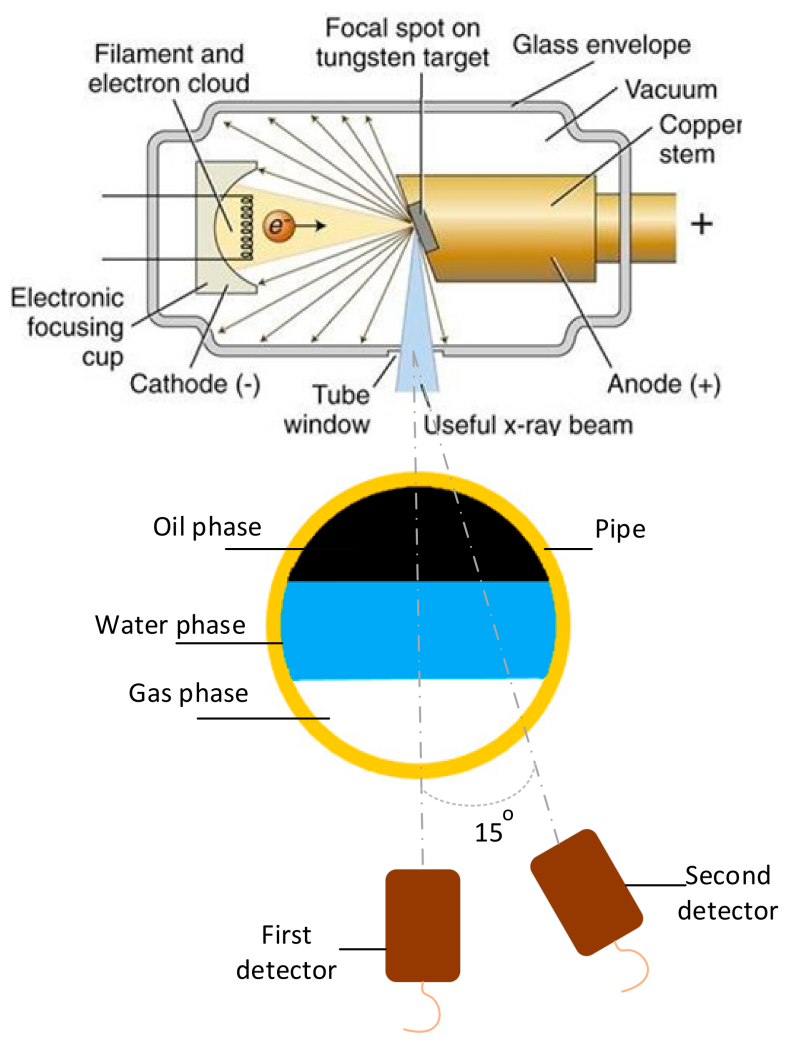

Figure 1. The structure of the simulated detection system using MCNPX.

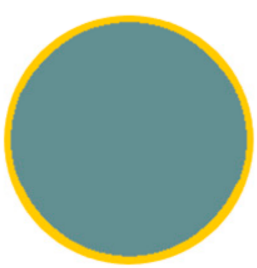

(a)

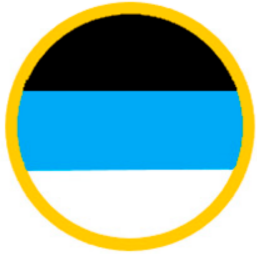

(b)

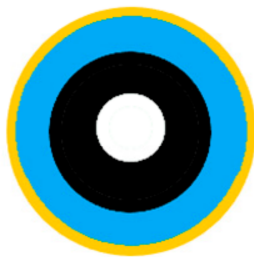

(c)

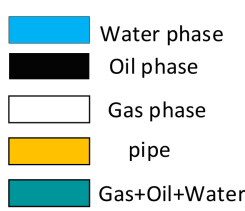

Figure 2. Simulated flow regimes: (a) homogenous (b) stratified (c) annular.

In this study, a typical industrial X-ray tube was used. The electron source and a tungsten/rubidium target were mounted in X-ray tubes as the cathode and anode, respectively. Complete X-ray tube simulation through MCNPX code, wherein a released electron from the cathode reacts to the anode and produces $X$-ray radiation, is timedemanding. Because the computation of photon tracking in MCNPX code is less than the electron, in this scrutiny, a source of photon inserted in an X-ray tube's shield was regarded 
for a cathode-anode assembly. TASMIC, a free package presented by Hernandez et al. [19], was applied. It is mentioned that various investigations have been conducted on X-ray spectra production via both theoretical and MCNP methods. Utilizing MCNPX code, Hernandez et al. produced an X-ray spectrum for diverse voltages of the tube. To define source energy, the achieved X-ray spectrum using the TASMIC package for $150 \mathrm{kV}$ as tube voltage was embedded into the input of MCNPX file by SI and SP choices in the SDEF card. The aforementioned source of the photon was inserted in a cylinder serving as an X-ray tube shield. On the shield surface, a section (the entitled output window) was left open for the releasing of the congenial produced X-ray photons. For filtration of low energy photons in this scrutiny, an aluminum filter with a thickness of $2.5 \mathrm{~mm}$ was placed against the output window of the X-ray tube.

\subsection{Frequency Domain Feature Extraction}

Feature extraction is performed from the measured raw data and provides a derivative amount of data that aims to reduce the size, eliminate useless data, facilitate the training process, and generalize the data. It also improves the interpretation of the data. When the available data is too large for processing, feature extraction methods are utilized to decrease the dimensions while preserving the properties of the data. When the amount of data available is large, not only is data analysis very difficult, but the designed detection system may be incompatible with the data set, and the detection system may be generalized to a limited set of data. There are various methods for feature extraction, such as feature extraction in the time, frequency, and time-frequency domain, and some innovative techniques that can be used (in proportion to raw data) to reduce the dimensions of the data. In this research, feature extraction in the frequency domain has been used, such that the FTT (Equation (1) [20]) was used to convert the received signals into the frequency domain. Then, the first and second dominant frequencies of the signals were extracted. As mentioned, two detectors have been used in this study and two characteristics have been extracted from each detector. Therefore, four characteristics were implemented for training the neural networks.

$$
Y(k)=\sum_{J=1}^{n} x(J) w_{n}^{(y-1)(k-1)}
$$

where $Y(k)=\operatorname{FFT}(\mathrm{X})$ and $w_{n}=e^{(-2 \pi i) / n}$ is one of $n$ roots of unity.

Figure 3 shows the received and converted signals into the frequency domain for all three mentioned flow regimes. 

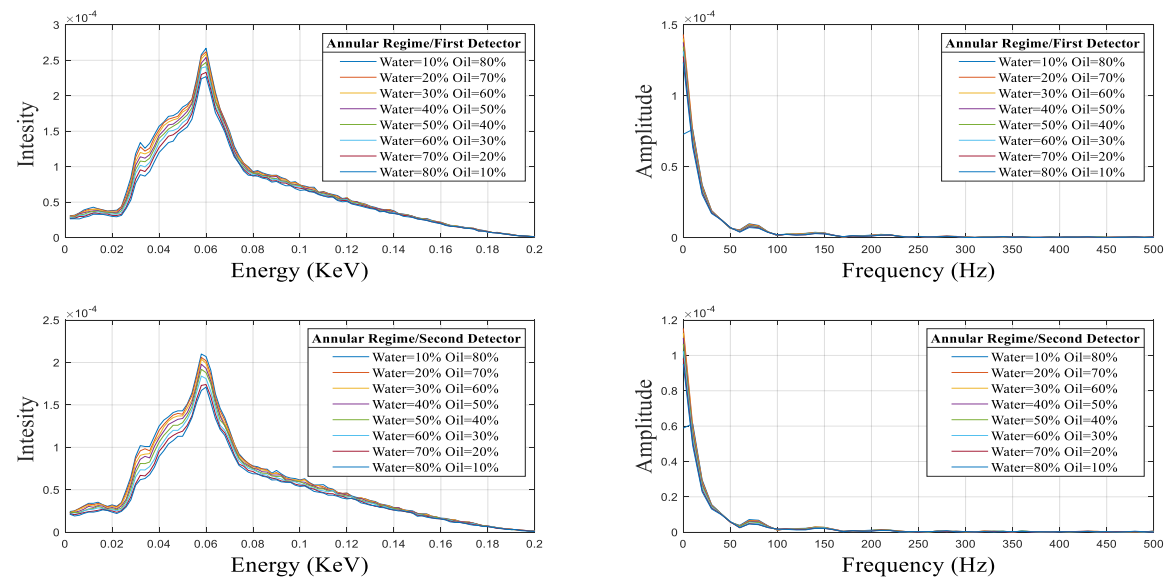

(a)
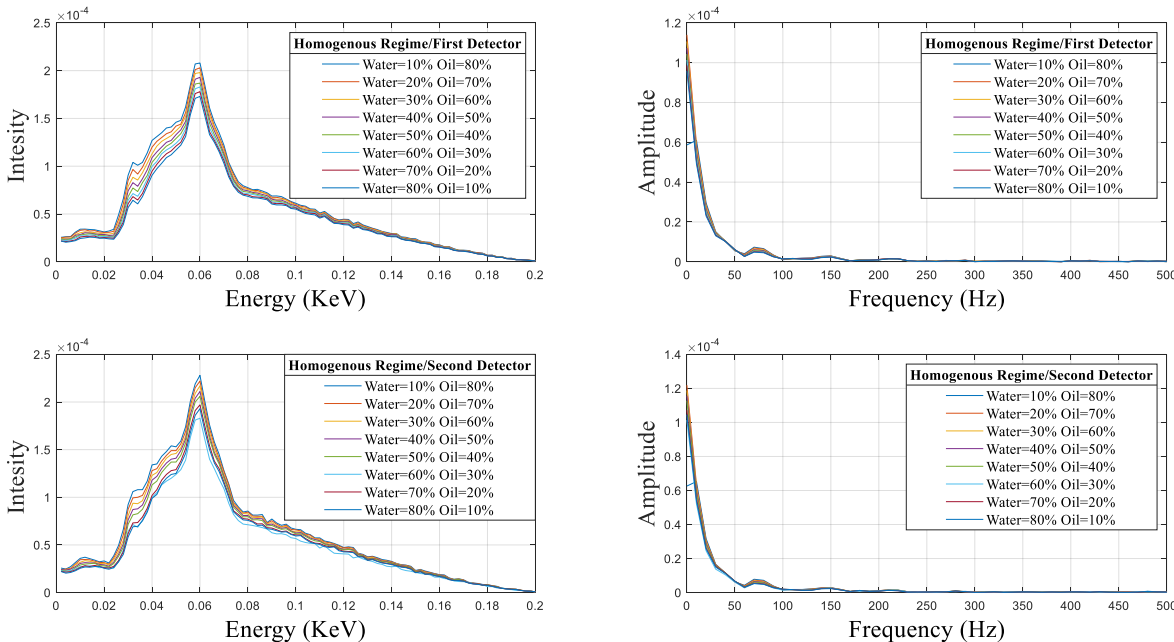

(b)
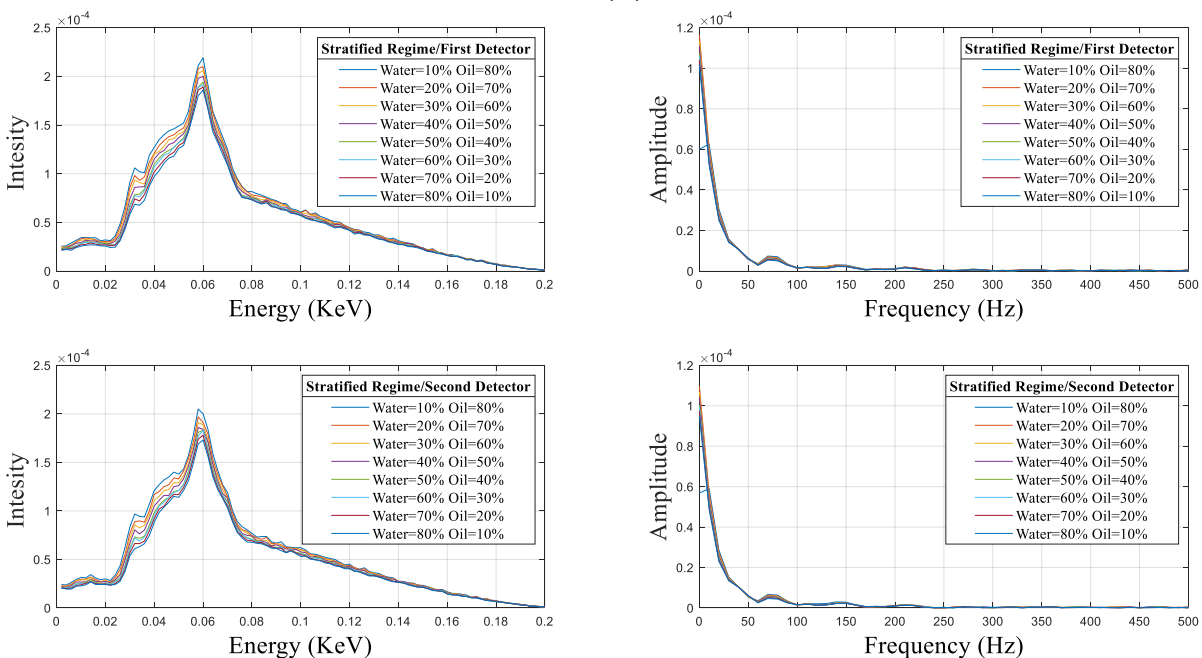

(c)

Figure 3. Recorded signals in time domain and converted signals into the frequency domain: (a) annular (b) homogenous (c) stratified flow regimes.

\subsection{RBF Neural Network}

In the last few years, various computational techniques have been utilized for various applications in the engineering research area [21-80]. RBF Neural Network is one of the 
most widely used neural networks that applies radial basis functions as an activation function. This network is used in many applications, such as function approximation, time series prediction, classification, and system control [81,82]. This neural network is a feedforward neural network, which consists of three layers called the input layer, the hidden layer, with a nonlinear activation function, and the output layer, with linear function [83]. The output of the $i$ th hidden neuron is obtained by the following equation [83]:

$$
z_{i}=k\left(\frac{\left\|x-r_{i}\right\|}{\sigma_{i}^{2}}\right) \quad i=1,2, \ldots, k
$$

where $k$ is the neurons number in the hidden layer, $\sigma_{i}$ is the width of the receptive field in the input space from unit $i, k$ is a strictly positive radially symmetric function (kernel) with a unique maximum at its center $\left(\mu_{i}\right)$, which drops off promptly to zero away from the center. This means that $z_{i}$ is a significant value when the distance of $\left\|x-\mu_{i}\right\|$ is less than the width of $\sigma_{i}$ [84]. By considering the input vector of $\mathrm{X}$, the output of the nth neuron of the output layer is obtained by [84]:

$$
y_{n}(x)=\sum_{i=1}^{k} w_{i n} z_{i}(x) \quad n=1,2, \ldots, N
$$

where $w_{\text {in }}$ is the weighting factor.

$$
\mathrm{E}(\mathrm{W})=\|\mathrm{HW}-\mathrm{Y}\|^{2}
$$

which $\mathrm{H}$ and $\mathrm{Y}$ are the outcome of radial basis functions and desired output, respectively [84].

The available data are divided into two categories: training and testing data. The use of test data in the network training process reassures us to avoid under-fitting and over-fitting problems.

\section{Results and Discussion}

In this study, three RBF neural networks have been designed to determine the type of flow regimes and detect volume percentages. The inputs of these networks are the first and second dominant frequencies of the recorded signals of both detectors. The ratio of data sharing as training data and test data is $70 \%$ to $30 \%$, respectively. The designed classifier network has four input neurons, 35 hidden neurons, and one output neuron. The configuration of the classifier network is shown in Table 1. The output of this network are the numbers 1,2, and 3, which are related to the annular, homogeneous, and stratified regimes, respectively. It should be noted that several thresholds are considered for the output of this network, so that the outputs between 0.5 and 1.5 are in the annular class, the outputs between 1.5 and 2.5 are in the homogeneous class, and the outputs between 2.5 and 3.5 are in the stratified class. Figure 4 shows the network structure of the classifier network, which is responsible for classifying flow regimes. Figure 5 illustrates the performance of this network for training and testing data using a confusion matrix, which represents $100 \%$ accuracy.

Table 1. Configuration of classifier network.

\begin{tabular}{cc}
\hline ANN Type & RBFNN \\
\hline Goal of Mean Squared Error (MSE) & 0 \\
\hline Radial basis functions spread & 4 \\
\hline Maximum neuron in hidden layer & 35 \\
\hline Number of neurons to add between each test & 1 \\
\hline
\end{tabular}




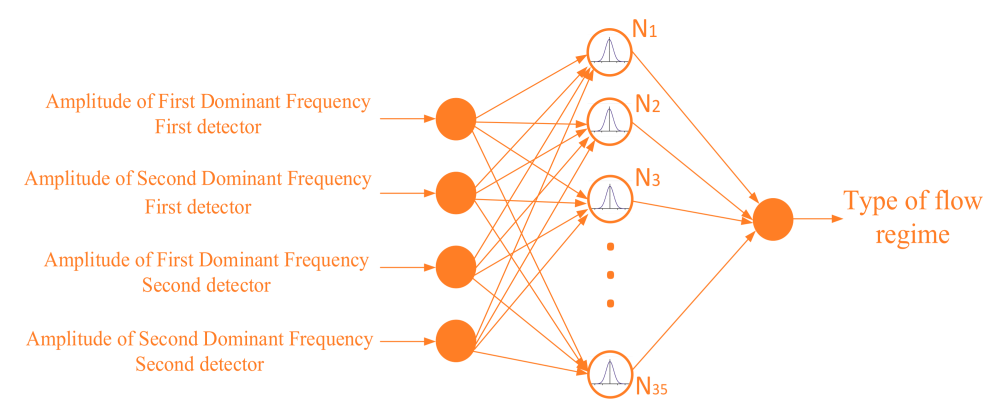

Figure 4. The structure of the flow regime classifier neural network.

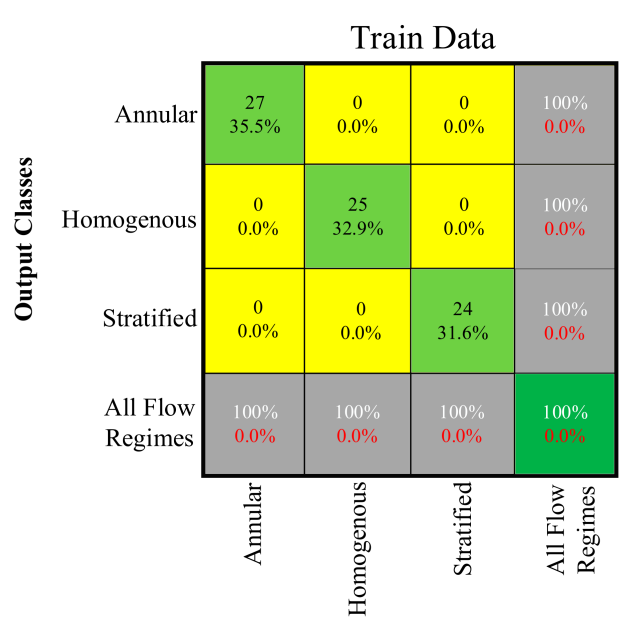

(a)

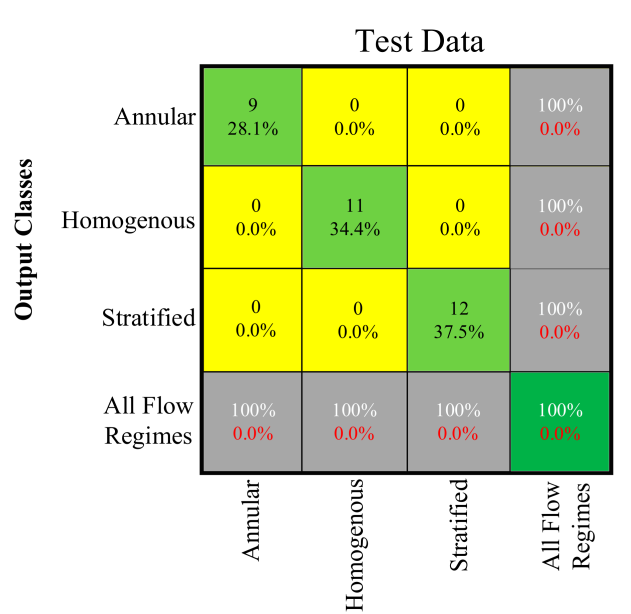

Target Classes

(b)

Figure 5. Performance of classifier network for (a) training and (b) testing data.

Two predictor neural networks are designed to determine the volume percentages of the gas phase and the water phase. It is necessary to say that, because the volume of the pipe is constant, by determining the volume percentage of the two phases, the volume percentage of the third phase is easily obtained. In this research, to show the performance of designed networks, a fit diagram (in which both network outputs and targets are plotted on a diagram), an error diagram, error histogram diagram, and a regression diagram have been illustrated. The structures of the neural networks used to estimate the volume percentage of the gas and water phases and the performance of these networks are shown in Figures 6-9, respectively. The configuration of the gas and water volume fraction predictor network is shown in Table 2.

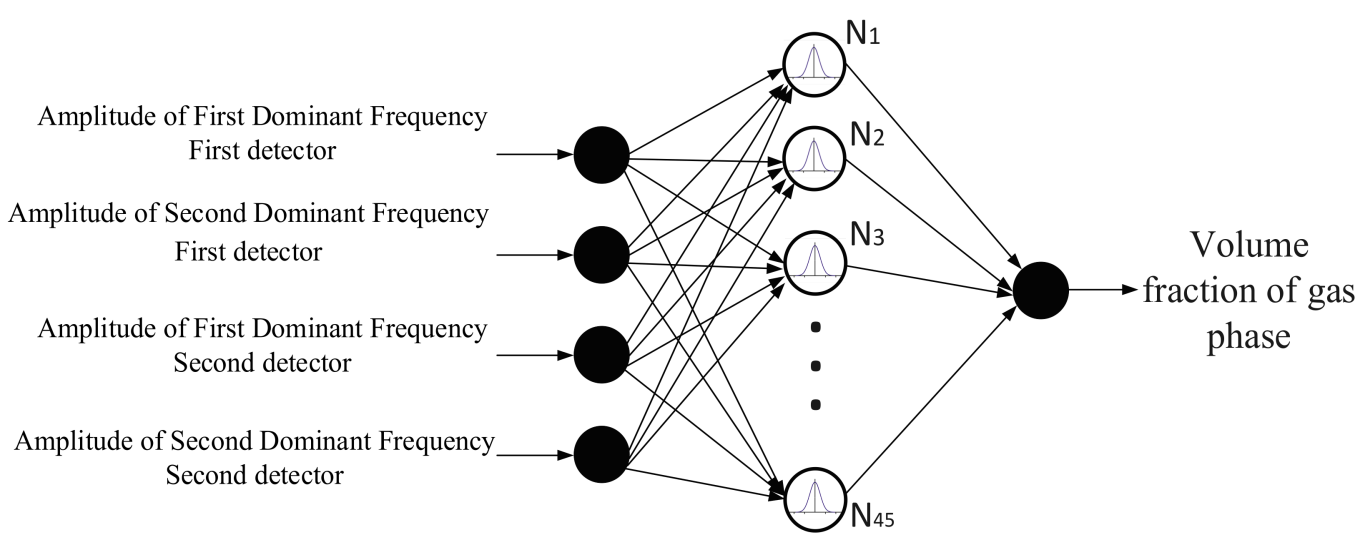

Figure 6. The structure of the gas phase volume fraction predictor RBF neural network. 


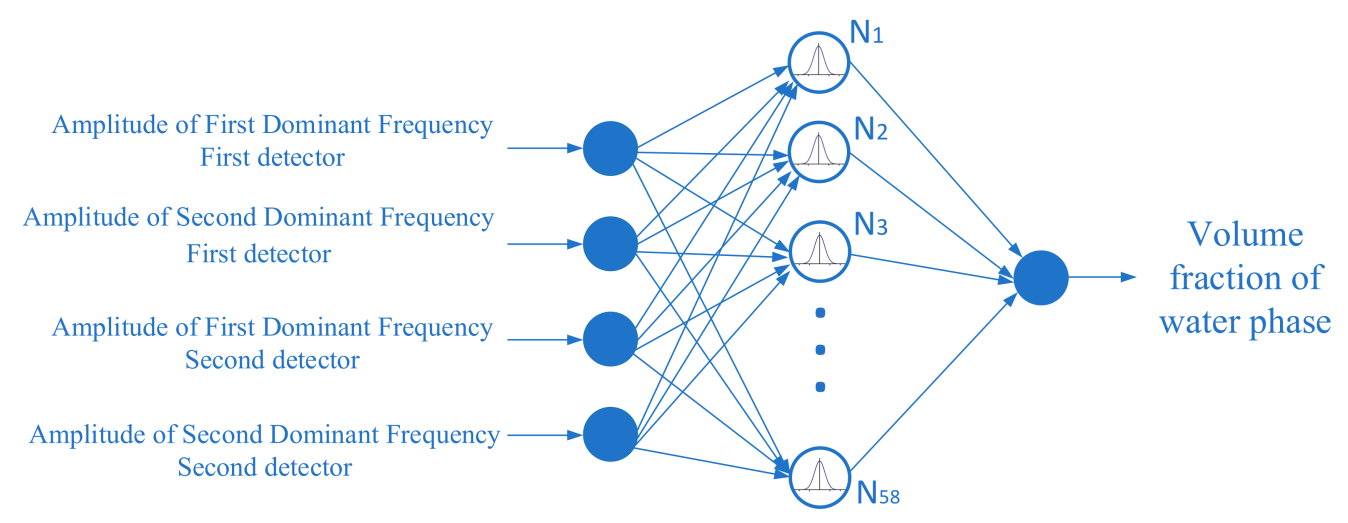

Figure 7. The structure of the water phase volume fraction predictor RBF neural network.
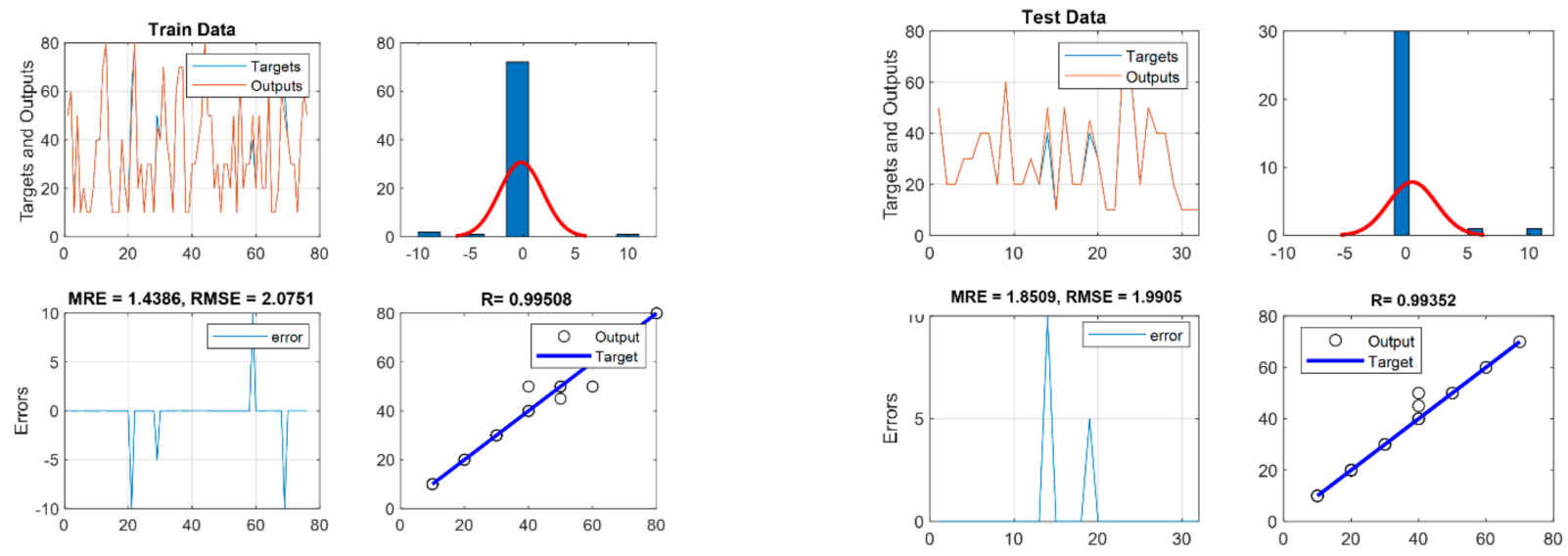

(a)

(b)

Figure 8. The fit diagram, the error histogram diagram, the error diagram, and the regression diagram to show the performance of the gas phase volume fraction predictor network for (a) train data (b) test data.
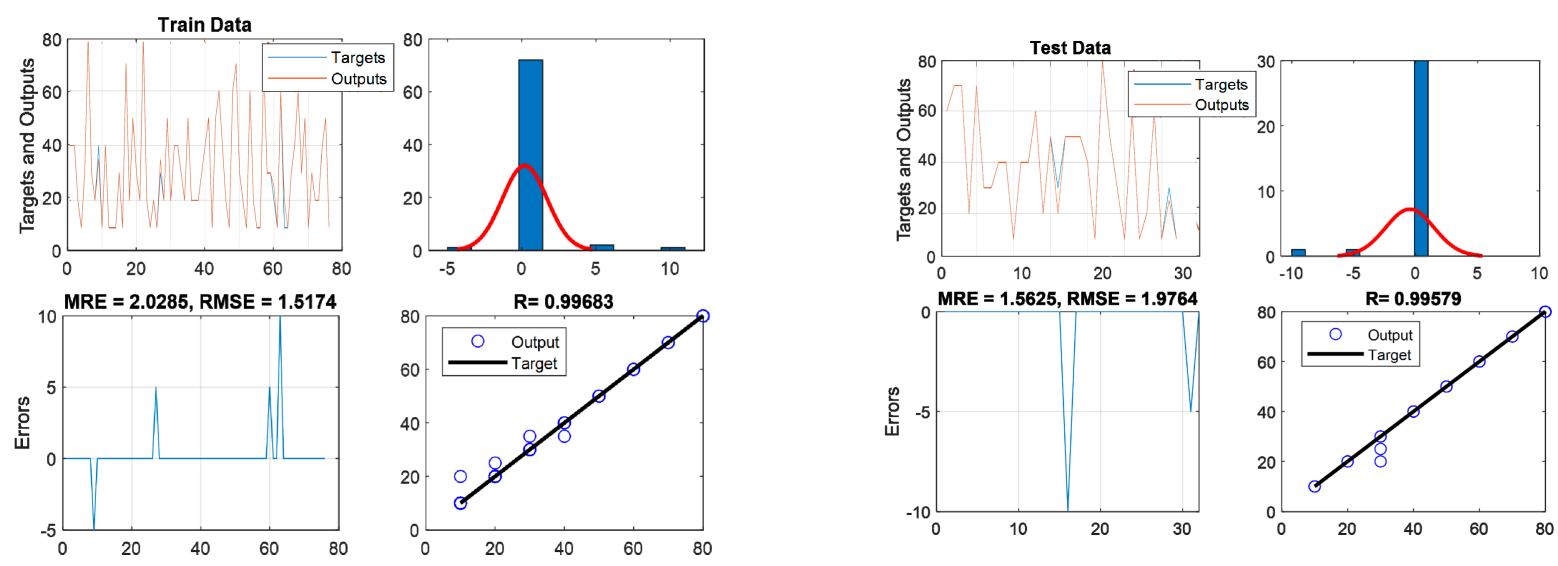

(a)

(b)

Figure 9. The fit diagram, the error histogram diagram, the error diagram, and the regression diagram to show the performance of the water phase volume fraction predictor network for (a) train data (b) test data. 
Table 2. Configuration of gas and water volume fraction predictor network.

\begin{tabular}{ccc}
\hline \multirow{2}{*}{ ANN Type } & \multicolumn{2}{c}{ RBFNN } \\
\cline { 2 - 3 } & Gas & Water \\
\hline Goal of Mean Squared Error (MSE) & 0 & 0 \\
\hline Radial basis functions spread & 4 & 3 \\
\hline Maximum neuron in hidden layer & 45 & 58 \\
\hline Number of neurons to add between each test & 1 & 1 \\
\hline
\end{tabular}

In fact, for the purpose of obtaining the optimal RBF model, several structures have been constructed and tested. The number of neurons was increased one by one from 1 neuron until the obtained error became almost constant. Until 35 neurons for classifier network, 45 neurons for gas volume fraction predictor network, and 58 neurons for water volume fraction predictor network, the errors changed meaningfully; however, after that, the error change was negligible. This behavior has been shown in Figures 10-12, which are performance graphs. In other words, selecting more neurons not only improves the performance of the neural network, but also increases the complexity of the designed networks.

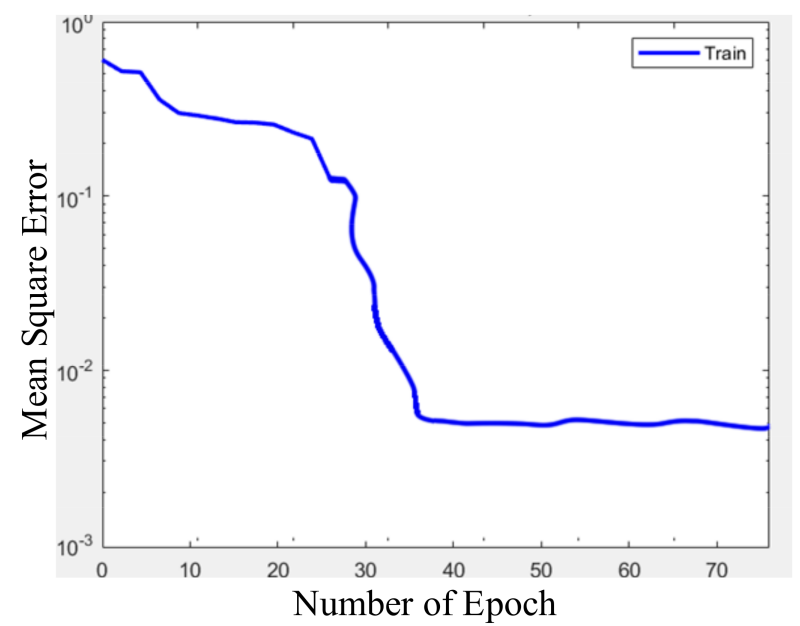

Figure 10. Performance graph of the flow regime classifier network.

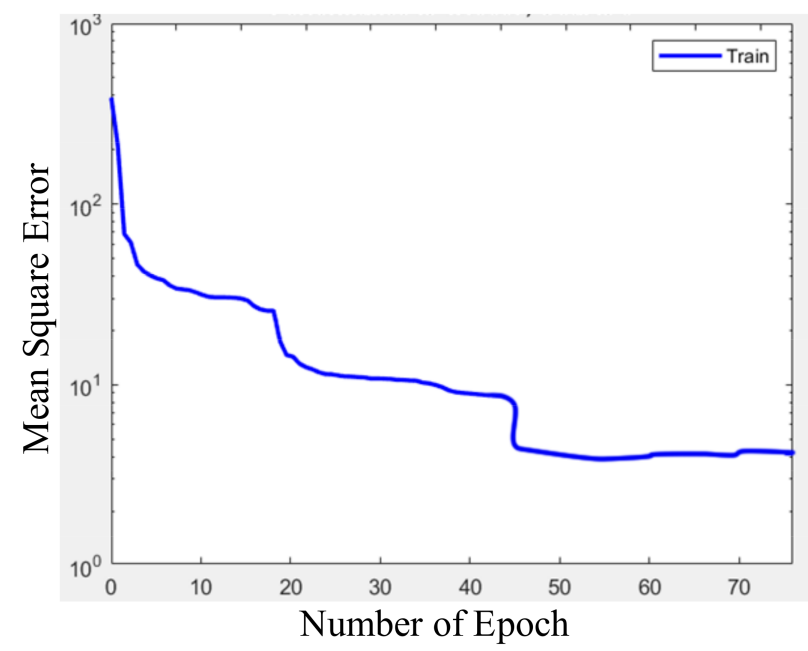

Figure 11. Performance graph of the gas volume fraction predictor network. 


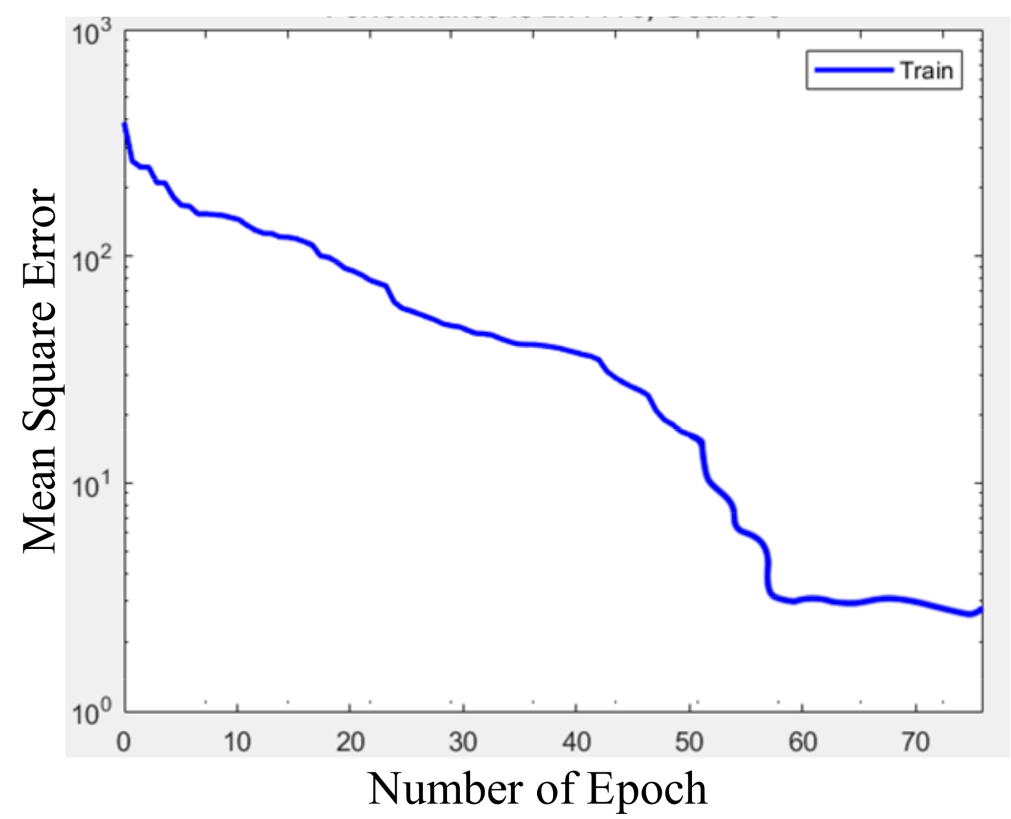

Figure 12. Performance graph of the water volume fraction predictor network.

To illustrate the performance of the designed networks, two error criteria, root mean square error (RMSE) and mean relative error $(M R E)$, are calculated as follows and tabulated in Table 3:

$$
\begin{aligned}
R M S E & =\left[\frac{\sum_{j=1}^{N}\left(X_{j}(E X P)-X_{j}(\text { pred })\right)^{2}}{N}\right]^{0.5} \\
M R E \% & =100 \times \frac{1}{N} \sum_{j=1}^{N}\left|\frac{X_{j}(E X P)-X_{j}(\text { pred })}{X_{j}(\text { pred })}\right|
\end{aligned}
$$

Table 3. Calculated the network's error.

\begin{tabular}{ccccc}
\hline Output & RMSE Train & MRE Train & RMSE Test & MRE Test \\
\hline Gas fraction & 2.07 & 1.43 & 1.99 & 1.85 \\
\hline Water fraction & 1.57 & 2.02 & 1.97 & 1.56 \\
\hline
\end{tabular}

A comparison between current research and previous studies is shown in Table 4. As is clear from the table, the use of frequency characteristics and RBF neural network is very effective in increasing the accuracy in determining the parameters of volume percentages and the type of flow regimes. It should be noted that the available data are often affected by uncertainty or imprecision, therefore it would be interesting to design non-destructive systems based on fuzzy logic approaches [85-87]. This subject could be used in future research in this area. 
Table 4. Comparison of the proposed method with some previous research.

\begin{tabular}{|c|c|c|c|c|c|}
\hline \multirow{2}{*}{ Reference } & \multirow{2}{*}{ Type of ANN } & \multirow{2}{*}{ Flow Regime } & \multirow{2}{*}{$\begin{array}{c}\text { Regime } \\
\text { Classification }\end{array}$} & \multicolumn{2}{|c|}{ Volume Fraction Prediction } \\
\hline & & & & MRE\% & RMSE \\
\hline$[2]$ & MLP & $\begin{array}{l}\text { Three Phase } \\
\text { (Stratified) }\end{array}$ & - & 6.47 & 1.6 \\
\hline$[17]$ & GMDH & $\begin{array}{c}\text { Three Phase } \\
\text { (Annular, Stratified, Homogenous) }\end{array}$ & Not completely & - & 5.39 \\
\hline$[88]$ & MLP & $\begin{array}{c}\text { Three Phase } \\
\text { (Annular, Stratified, Homogenous) }\end{array}$ & Completely & 3.5 & - \\
\hline [89] & $\begin{array}{l}\text { Jaya optimization algorithm } \\
\text { and neuro-fuzzy network }\end{array}$ & $\begin{array}{l}\text { Three Phase } \\
\text { (Stratified) }\end{array}$ & - & 1.31 & 0.56 \\
\hline$[90]$ & $\begin{array}{l}\text { adaptive neuro-fuzzy } \\
\text { inference system }\end{array}$ & $\begin{array}{l}\text { Three Phase } \\
\text { (Annular) }\end{array}$ & - & 2.73 & - \\
\hline$[91]$ & MLP & $\begin{array}{l}\text { Three Phase } \\
\text { (Stratified) }\end{array}$ & - & 4.64 & 1.49 \\
\hline [92] & MLP & $\begin{array}{l}\text { Three Phase } \\
\text { (Stratified) }\end{array}$ & - & 7.08 & 2.48 \\
\hline This study & RBF & $\begin{array}{c}\text { Three Phase } \\
\text { (Annular, Stratified, Homogenous) }\end{array}$ & completely & 2.02 & 2.07 \\
\hline
\end{tabular}

\section{Conclusions}

In this study, the application of characteristics of the signal in the frequency domain as well as the RBF neural network to determine the type of flow regimes and volume percentages in three-phase flows have been investigated. The structure of the detection system, which consists of an X-ray tube, a Pyrex-glass, and two NaI detectors, was implemented using the MCNP-X code. From each received signal, two characteristics named amplitude of the first and second dominant frequency were extracted and used as neural network inputs for network training. As a result, three networks were implemented to diagnose the type of flow patterns and determine the gas and water phase volume percentages. Reducing the error in determining the mentioned parameters due to the use of frequency characteristics and the RBF network is a great achievement of this research.

Author Contributions: Conceptualization, M.A.S. and O.T.; Software, I.E.E., M.A.S., O.T.; WritingReview and Editing, M.A.S., E.N., O.T. and I.E.E.; Funding acquisition, I.E.E., O.T. All authors have read and agreed to the published version of the manuscript.

Funding: This work was funded by the Deanship of Scientific Research (DSR), King Abdulaziz University, Jeddah, under grant No. (IFPHI-289-135-2020). The authors, therefore, acknowledge with thanks DSR technical and financial support.

Institutional Review Board Statement: Not applicable.

Informed Consent Statement: Not applicable.

Data Availability Statement: Data is contained within the article.

Conflicts of Interest: The authors declare no conflict of interest.

\section{References}

1. Roshani, G.H.; Feghhi, S.A.H.; Mahmoudi-Aznaveh, A.; Nazemi, E.; Adineh-Vand, A. Precise volume fraction prediction in oilwater-gas multiphase flows by means of gamma-ray attenuation and artificial neural networks using one detector. Measurement 2014, 51, 34-41. [CrossRef]

2. Peyvandi, R.G.; Rad, S.Z.I. Application of artificial neural networks for the prediction of volume fraction using spectra of gamma rays backscattered by three-phase flows. Eur. Phys. J. Plus 2017, 132, 511. [CrossRef]

3. Sattari, M.A.; Roshani, G.H.; Hanus, R.; Nazemi, E. Applicability of time-domain feature extraction methods and artificial intelligence in two-phase flow meters based on gamma-ray absorption technique. Measurement 2021, 168, 108474. [CrossRef]

4. Sattari, M.A.; Roshani, G.H.; Hanus, R. Improving the structure of two-phase flow meter using feature extraction and GMDH neural network. Radiat. Phys. Chem. 2020, 171, 108725. [CrossRef]

5. Roshani, G.H.; Nazemi, E.; Roshani, M.M. Intelligent recognition of gas-oil-water three-phase flow regime and determination of volume fraction using radial basis function. Flow Meas. Instrum. 2017, 54, 39-45. [CrossRef] 
6. Hanus, R.; Zych, M.; Petryka, L.; Jaszczur, M.; Hanus, P. Signals features extraction in liquid-gas flow measurements using gamma densitometry. Part 1: Time domain. EPJ Web Conf. 2016, 114, 02035. [CrossRef]

7. Hanus, R.; Zych, M.; Petryka, L.; Jaszczur, M.; Hanus, P. Signals features extraction in liquid-gas flow measurements using gamma densitometry. Part 2: Frequency domain. EPJ Web Conf. 2016, 114, 02036. [CrossRef]

8. Hanus, R.; Zych, M.; Kusy, M.; Jaszczur, M.; Petryka, L. Identification of liquid-gas flow regime in a pipeline using gamma-ray absorption technique and computational intelligence methods. Flow Meas. Instrum. 2018, 60, 17-23. [CrossRef]

9. Hosseini, S.; Roshani, G.H.; Setayeshi, S. Precise gamma based two-phase flow meter using frequency feature extraction and only one detector. Flow Meas. Instrum. 2020, 72, 101693. [CrossRef]

10. Roshani, G.H.; Nazemi, E.; Feghhi, S.A.H. Investigation of using 60Co source and one detector for determining the flow regime and void fraction in gas-liquid two-phase flows. Flow Meas. Instrum. 2016, 50, 73-79. [CrossRef]

11. Roshani, G.H.; Nazemi, E.; Feghhi, S.A.; Setayeshi, S. Flow regime identification and void fraction prediction in two-phase flows based on gamma ray attenuation. Measurement 2015, 62, 25-32. [CrossRef]

12. Nazemi, E.; Roshani, G.H.; Feghhi, S.A.H.; Setayeshi, S.; Zadeh, E.E.; Fatehi, A. Optimization of a method for identifying the flow regime and measuring void fraction in a broad beam gamma-ray attenuation technique. Int. J. Hydrogen Energy 2016, 41, 7438-7444. [CrossRef]

13. Roshani, G.H.; Nazemi, E.; Roshani, M.M. Flow regime independent volume fraction estimation in three-phase flows using dual-energy broad beam technique and artificial neural network. Neural Comput. Appl. 2016, 28, 1265-1274. [CrossRef]

14. Nazemi, E.; Feghhi, S.A.H.; Roshani, G.H.; Peyvandi, R.G.; Setayeshi, S. Precise Void Fraction Measurement in Two-phase Flows Independent of the Flow Regime Using Gamma-ray Attenuation. Nucl. Eng. Technol. 2016, 48, 64-71. [CrossRef]

15. Song, K.; Liu, Y. A compact X-ray system for two-phase flow measurement. Meas. Sci. Technol. 2017, 29, 025305. [CrossRef]

16. Roshani, M.; Ali, P.J.M.; Roshani, G.H.; Nazemi, B.; Corniani, E.; Phan, N.-H.; Tran, H.-N.; Nazemi, E. X-ray tube with artificial neural network model as a promising alternative for radioisotope source in radiation based two phase flowmeters. Appl. Radiat. Isot. 2020, 164, 109255. [CrossRef]

17. Roshani, M.; Phan, G.; Roshani, G.H.; Hanus, R.; Nazemi, B.; Corniani, E.; Nazemi, E. Combination of X-ray tube and GMDH neural network as a nondestructive and potential technique for measuring characteristics of gas-oil-water three phase flows. Measurement 2021, 168, 108427. [CrossRef]

18. Roshani, G.H.; Ali, P.J.M.; Mohammed, S.; Hanus, R.; Abdulkareem, L.; Alanezi, A.A.; Nazemi, E.; Eftekhari-Zadeh, E.; Kalmoun, E.M. Feasibility Study of Using X-ray Tube and GMDH for Measuring Volume Fractions of Annular and Stratified Regimes in Three-Phase Flows. Symmetry 2021, 13, 613. [CrossRef]

19. Hernandez, A.M.; Boone, J.M. Tungsten anode spectral model using interpolating cubic splines: Unfiltered x-ray spec-tra from $20 \mathrm{kV}$ to $640 \mathrm{kV}$. Med. Phys. 2014, 41, 042101. [CrossRef]

20. Nussbaumer, H.J. The fast Fourier transform. In Fast Fourier Transform and Convolution Algorithms; Springer: Berlin, Germany, 1981; pp. 80-111.

21. Versaci, M.; Morabito, F.C. Image Edge Detection: A New Approach Based on Fuzzy Entropy and Fuzzy Divergence. Int. J. Fuzzy Syst. 2021, 23, 918-936. [CrossRef]

22. Karami, A.; Roshani, G.H.; Khazaei, A.; Nazemi, E.; Fallahi, M. Investigation of different sources in order to optimize the nuclear metering system of gas-oil-water annular flows. Neural Comput. Appl. 2018, 32, 3619-3631. [CrossRef]

23. Burrascano, P.; Ciuffetti, M. Early Detection of Defects through the Identification of Distortion Characteristics in Ultrasonic Responses. Math 2021, 9, 850. [CrossRef]

24. Farahani, A.; Voghoei, S.; Rasheed, K.; Arabnia, H.R. A Brief Review of Domain Adaptation. arXiv 2020, arXiv:2010.03978.

25. Roshani, M.; Phan, G.; Faraj, R.H.; Phan, N.H.; Roshani, G.H.; Nazemi, B.; Corniani, E.; Nazemi, E. Proposing a gamma ra-di-ation based intelligent system for simultaneous analyzing and detecting type and amount of petroleum by-products. Neural Eng. Technol. 2021, 53, 1277-1283.

26. Hassan, A.S.; Meyer, D.F. Analysis of The Non-Linear Effect of Petrol Price Changes on Inflation in South Africa. Int. J. Soc. Sci. Humanit. Stud. 2020, 12, 34-49.

27. Mosorov, V.; Rybak, G.; Sankowski, D. Plug Regime Flow Velocity Measurement Problem Based on Correlability Notion and Twin Plane Electrical Capacitance Tomography: Use Case. Sensors 2021, 21, 2189. [CrossRef] [PubMed]

28. Roshani, G.; Hanus, R.; Khazaei, A.; Zych, M.; Nazemi, E.; Mosorov, V. Density and velocity determination for single-phase flow based on radiotracer technique and neural networks. Flow Meas. Instrum. 2018, 61, 9-14. [CrossRef]

29. Versaci, M.; Angiulli, G.; Di Barba, P.; Morabito, F.C. Joint use of eddy current imaging and fuzzy similarities to assess the integrity of steel plates. Open Phys. 2020, 18, 230-240. [CrossRef]

30. Roshani, M.; Phan, G.T.; Ali, P.J.M.; Roshani, G.H.; Hanus, R.; Duong, T.; Corniani, E.; Nazemi, E.; Kalmoun, E.M. Evaluation of flow pattern recognition and void fraction measurement in two phase flow independent of oil pipeline's scale layer thickness. Alex. Eng. J. 2021, 60, 1955-1966. [CrossRef]

31. Aghakhani, M.; Ghaderi, M.R.; Karami, A.; Derakhshan, A.A. Combined effect of TiO2 nanoparticles and input welding parameters on the weld bead penetration in submerged arc welding process using fuzzy logic. Int. J. Adv. Manuf. Technol. 2014, 70, 63-72. [CrossRef]

32. Pirasteh, A.; Roshani, S.; Roshani, S. Compact microstrip lowpass filter with ultrasharp response using a square-loaded modified T-shaped resonator. Turk. J. Electr. Eng. Comput. Sci. 2018, 26, 1736-1746. [CrossRef] 
33. Bhore, S.J.; Cha, T.S.; Amelia, K.; Shah, F.H. Insights from computational analysis of full-length $\beta$-ketoacyl-[ACP] synthase-II cDNA isolated from American and African oil palms. J. Nat. Sci. Biol. Med. 2014, 5, 73-81. [CrossRef]

34. Moradi, M.J.; Roshani, M.M.; Shabani, A.; Kioumarsi, M. Prediction of the Load-Bearing Behavior of SPSW with Rectangular Opening by RBF Network. Appl. Sci. 2020, 10, 1185. [CrossRef]

35. Karimi, M.; Kim, H. Energy scheduling for task execution on intermittently-powered devices. ACM SIGBED Rev. 2020, $17,36-41$. [CrossRef]

36. Roshani, G.H.; Roshani, S.; Nazemi, E.; Roshani, S. Online measuring density of oil products in annular regime of gas-liquid two phase flows. Measurement 2018, 129, 296-301. [CrossRef]

37. Karami, A.; Veysi, F. A novel metaheuristic combinatorial algorithm to optimize the natural convection across a vertical enclosure divided by perforated flat horizontal louvers inside. Eur. Phys. J. Plus 2021, 136, 1-33. [CrossRef]

38. Roshani, S.; Roshani, S. Design of a very compact and sharp bandpass diplexer with bended lines for GSM and LTE applications. AEU Int. J. Electron. Commun. 2019, 99, 354-360. [CrossRef]

39. Hanus, R.; Zych, M.; Mosorov, V.; Golijanek-Jędrzejczyk, A.; Jaszczur, M.; Andruszkiewicz, A. Evaluation of liquid-gas flow in pipeline using gamma-ray absorption technique and advanced signal processing. Metrol. Meas. Syst. 2021, 28, 145-159.

40. Roshani, S.; Roshani, S.; Zarinitabar, A. A modified Wilkinson power divider with ultra harmonic suppression using open stubs and lowpass filters. Analog. Integr. Circuits Signal Process. 2019, 98, 395-399. [CrossRef]

41. Niccolai, A.; Caputo, D.; Chieco, L.; Grimaccia, F.; Mussetta, M. Machine Learning-Based Detection Technique for NDT in Industrial Manufacturing. Math 2021, 9, 1251. [CrossRef]

42. Dunga, H.M. An empirical analysis on determinants of food security among female-headed households in South Af-rica. Int. J. Soc. Sci. Humanit. Stud. 2020, 12, 66-81.

43. Basahel, A.; Sattari, M.A.; Taylan, O.; Nazemi, E. Application of Feature Extraction and Artificial Intelligence Techniques for Increasing the Accuracy of X-ray Radiation Based Two Phase Flow Meter. Mathematics 2021, 9, 1227. [CrossRef]

44. Roshani, G.; Nazemi, E.; Roshani, M. Identification of flow regime and estimation of volume fraction independent of liquid phase density in gas-liquid two-phase flow. Prog. Nucl. Energy 2017, 98, 29-37. [CrossRef]

45. Karami, A.; Yousefi, T.; Harsini, I.; Maleki, E.; Mahmoudinezhad, S. Neuro-Fuzzy Modeling of the Free Convection Heat Transfer from a Wavy Surface. Heat Transf. Eng. 2014, 36, 847-855. [CrossRef]

46. Moradi, M.; Daneshvar, K.; Ghazi-Nader, D.; Hajiloo, H. The prediction of fire performance of concrete-filled steel tubes (CFST) using artificial neural network. Thin-Walled Struct. 2021, 161, 107499. [CrossRef]

47. Rodriguez, A.; Mokoena, M.; Corcho, F.; Bisetty, K.; Perez, J. Computational study of the folded structure of the miniprotein CLN025 in explicit and implicit solvents. J. Nat. Sci. Biol. Med. 2011, 2, 2229-7707.

48. Jamshidi, M.B.; Siahkamari, H.; Roshani, S.; Roshani, S. A compact Gysel power divider design using U-shaped and T-shaped resonators with harmonics suppression. Electromagnetics 2019, 39, 491-504. [CrossRef]

49. David, O.O.; Grobler, W. Age Progression, Social Interventions and Food Insecurity in South Africa: Logistic Re-gression Analysis. Int. J. Soc. Sci. Humanit. Stud. 2020, 12, 289-305.

50. Roshani, G.; Nazemi, E. Intelligent densitometry of petroleum products in stratified regime of two phase flows using gamma ray and neural network. Flow Meas. Instrum. 2017, 58, 6-11. [CrossRef]

51. Arab, F.; Karimi, M.; Safavi, S.M. Analysis of QoS parameters for video traffic in homeplug AV stand-ard using NS-3. In Proceedings of the 2016 Smart Grids Conference (SGC), Kerman, Iran, 20-21 December 2016; pp. 1-6.

52. Roshani, G.; Nazemi, E.; Roshani, M. Usage of two transmitted detectors with optimized orientation in order to three phase flow metering. Measurement 2017, 100, 122-130. [CrossRef]

53. Jamshidi, M.B.; Roshani, S.; Talla, J.; Roshani, S.; Peroutka, Z. Size reduction and performance improvement of a microstrip Wilkinson power divider using a hybrid design technique. Sci. Rep. 2021, 11, 1-15. [CrossRef]

54. Moradi, M.J.; Hariri-Ardebili, M.A. Developing a Library of Shear Walls Database and the Neural Network Based Predictive Meta-Model. Appl. Sci. 2019, 9, 2562. [CrossRef]

55. Alkabaa, A.S.; Nazemi, E.; Taylan, O.; Kalmoun, E.M. Application of Artificial Intelligence and Gamma Attenuation Techniques for Predicting Gas-Oil-Water Volume Fraction in Annular Regime of Three-Phase Flow Independent of Oil Pipeline's Scale Layer. Mathematics 2021, 9, 1460. [CrossRef]

56. Roshani, S.; Roshani, S. Two-Section Impedance Transformer Design and Modeling for Power Amplifier Applications. Ap-Plied Comput. Electromagn. Soc. J. 2017, 32, 1042-1047.

57. Zych, M.; Hanus, R.; Vlasak, P.; Jaszczur, M.; Petryka, L. Radiometric methods in the measurement of particle-laden flows. Powder Technol. 2017, 318, 491-500. [CrossRef]

58. Pirasteh, A.; Roshani, S.; Roshani, S. A modified class-F power amplifier with miniaturized harmonic control circuit. AEU Int. J. Electron. Commun. 2018, 97, 202-209. [CrossRef]

59. Hussain, M.; Banday, A.; Tabish, M. Computational prediction and identification of new splice variant of PKA catalytic alpha subunit gene in mouse. J. Nat. Sci. Biol. Med. 2011, 2, 687-693.

60. Kharazmi, O.; Jahangard, S. A new family of lifetime distributions in terms of cumulative hazard rate function. Commun. Fac. Sci. Univ. Ank. Ser. A1Math. Stat. 2020, 69, 1-22. [CrossRef]

61. Kharazmi, O.; Saadatinik, A.; Jahangard, S. Odd Hyperbolic Cosine Exponential-Exponential (OHC-EE) Distribution. Ann. Data Sci. 2019, 6, 765-785. [CrossRef] 
62. Hayerikhiyavi, M.; Dimitrovski, A. Gyrator-Capacitor Modeling of a Continuously Variable Series Reactor in Different Operating Modes. In Proceedings of the 2021 IEEE Kansas Power and Energy Conference (KPEC), Manhattan, KS, USA, 19-20 April 2021; pp. 1-5.

63. Hayerikhiyavi, M.; Dimitrovski, A. A Practical Assessment of the Power Grid Inertia Constant Using PMUs. In Proceedings of the 2020 52nd North American Power Symposium (NAPS), Tempe, AZ, USA, 11-13 October 2021; pp. 1-5.

64. Sarhadi, M.; Aryan, L.; Zarei, M. The Estrogen Receptor and Breast Cancer: A Complete Review. CRPASE 2020, 6, 309-314.

65. Sadeghi, H.; Bordbar, H.; Hostikka, S. Generating Emissivity Charts for Fuel Gases from High-Resolution Spectral Absorption Data. In Proceedings of the 18th Brazilian Congress of Thermal Sciences and Engineering, online, 16-20 November 2020. [CrossRef]

66. Sadeghi, H.; Bordbar, H.; Hostikka, S. An Assessment of Wsgg Model for Calculation of Radiative Heat Flux in fds, January 2020. In Proceedings of the 18th Brazilian Congress of Thermal Sciences and Engineering, online, 16-20 November 2020. [CrossRef]

67. Chapnevis, A.; Guvenc, I.; Bulut, E. Traffic Shifting based Resource Optimization in Aggregated IoT Communication. In Proceedings of the 2020 IEEE 45th Conference on Local Computer Networks (LCN), Sydney, Australia, 16-19 November 2020; pp. 233-243.

68. Arasteh, S.; Mahdavi, M.; Bideh, P.N.; Hosseini, S.; Chapnevis, A. Security Analysis of two Key Based Wa-termarking Schemes Based on QR Decomposition. In Proceedings of the Iranian Conference on Electrical Engineering (ICEE), Mashhad, Iran, 8-10 May 2018; pp. 1499-1504.

69. Chapnevis, A.; Sadeghiyan, B. A Secure Two-Party Computation Protocol for Intersection Detection between Two Convex Hulls. arXiv 2020, arXiv:2011.00319.

70. Ashrafi, R.; Azarbayjani, M.; Cox, R.; Futrell, B.; Glass, J.; Zarrabi, A.; Amirazar, A. Assessing the Performance of UFAD System in an Office Building Located in Various Climate Zones. In Proceedings of the Symposium on Simulation for Architecture and Urban Design, Atlanta, GA, USA, 7-9 April 2019.

71. Gukeh, M.J.; Roy, T.; Sen, U.; Ganguly, R.; Megaridis, C.M. Lateral Spreading of Gas Bubbles on Submerged Wettability-Confined Tracks. Langmuir 2020, 36, 11829-11835. [CrossRef] [PubMed]

72. Bernardini, J.; Sen, U.; Jafari Gukeh, M.; Asinari, P.; Megaridis, C.M. Wettability-Engineered Meshes for Gas Mi-crovolume Precision Handling in Liquids. ACS Appl. Mater. Interfaces 2020, 12, 18046-18055. [CrossRef] [PubMed]

73. Damoulakis, G.; Jafari-Gukeh, M.; Koukoravas, T.P.; Megaridis, C. High-performance Planar Thermal Diode with Wickless Components. J. Electron. Packag. 2021, in press. [CrossRef]

74. Seyedi, M.; Taher, S.A.; Ganji, B.; Guerrero, J. A Hybrid Islanding Detection Method Based on the Rates of Chang-es in Voltage and Active Power for the Multi-Inverter Systems. IEEE Trans. Smart Grid 2021, 12, 2800-2811. [CrossRef]

75. Roshani, M.; Sattari, M.A.; Ali, P.J.M.; Roshani, G.H.; Nazemi, B.; Corniani, E.; Nazemi, E. Application of GMDH neural network technique to improve measuring precision of a simplified photon attenuation based two-phase flowmeter. Flow Meas. Instrum. 2020, 75, 101804. [CrossRef]

76. Hashemi Tonekaboni, N.; Voghoei, S.; Yazdansepas, D. How Personalized Feedback Emails Can En-hance Participation Rate in Online Courses. In Proceedings of the 51st ACM Technical Symposium on Computer Science Education, New York, NY, USA, 11-14 March 2020; p. 1376.

77. Salimi, J.; Ramezanianpour, A.M.; Moradi, M.J. Studying the effect of low reactivity metakaolin on free and restrained shrinkage of high performance concrete. J. Build. Eng. 2020, 28, 101053. [CrossRef]

78. Jahanshahi, A.; Taram, M.K.; Eskandari, N. Blokus Duo game on FPGA. In Proceedings of the 17th CSI International Symposium on Computer Architecture \& Digital Systems (CADS 2013), Tehran, Iran, 30-31 October 2013; pp. 149-152.

79. Roshani, S.; Roshani, S. Design of a high efficiency class-F power amplifier with large signal and small signal measurements. Measurement 2020, 149, 106991. [CrossRef]

80. Rashidisabet, H.; Thomas, P.J.; Ajilore, O.; Zulueta, J.; Moore, R.C.; Leow, A. A systems biology approach to the digital behaviorome. Curr. Opin. Syst. Biol. 2020, 20, 8-16. [CrossRef]

81. Haykin, S. Neural Networks: A Comprehensive Foundation, 2nd ed.; Prentice-Hall Inc.: Upper Saddle River, NJ, USA, $1999 ;$ p. 842.

82. Shahsavand, A.; Ahmadpour, A. Application of optimal RBF neural networks for optimization and characterization of porous materials. Comput. Chem. Eng. 2005, 29, 2134-2143. [CrossRef]

83. Yu, B.; He, X. Training radial basis function networks with differential evolution. IEEE Int. Conf. Granul. Comput. 2006, 11, 369-372. [CrossRef]

84. Hartman, E.J.; Keeler, J.D.; Kowalski, J.M. Layered neural networks with Gaussian hidden units as universal approxima-tors. Neural Comput. 1990, 2, 210-215. [CrossRef]

85. Cacciola, M.; La Foresta, F.; Morabito, F.C.; Versaci, M. Advanced use of soft computing and eddy current test to evaluate mechanical integrity of metallic plates. NDT E Int. 2007, 40, 357-362. [CrossRef]

86. Ghanei, S.; Vafaeenezhad, H.; Kashefi, M.; Eivani, A.; Mazinani, M. Design of an expert system based on neuro-fuzzy inference analyzer for on-line microstructural characterization using magnetic NDT method. J. Magn. Magn. Mater. 2015, 379, 131-136. [CrossRef]

87. Naik, S.; Patel, B.; Pandey, R. Shape, size and maturity features extraction with fuzzy classifier for non-destructive mango (Mangifera Indica, L., cv. Kesar) grading. In Proceedings of the 2015 IEEE Technological Innovation in ICT for Agriculture and Rural Development (TIAR), Chennai, India, 10-12 July 2015; pp. 1-7. 
88. Salgado, C.M.; Pereira, C.M.; Schirru, R.; Brandão, L.E. Flow regime identification and volume fraction prediction in multiphase flows by means of gamma-ray attenuation and artificial neural networks. Prog. Nucl. Energy 2010, 52, 555-562. [CrossRef]

89. Karami, A.; Roshani, G.H.; Nazemi, E.; Roshani, S. Enhancing the performance of a dual-energy gamma ray based three-phase flow meter with the help of grey wolf optimization algorithm. Flow Meas. Instrum. 2018, 64, 164-172. [CrossRef]

90. Roshani, G.H.; Karami, A.; Nazemi, E.; Shama, F. Volume fraction determination of the annular three-phase flow of gas-oil-water using adaptive neuro-fuzzy inference system. Comput. Appl. Math. 2018, 37, 4321-4341. [CrossRef]

91. Rad, S.I.; Peyvandi, R.G. A simple and inexpensive design for volume fraction prediction in three-phase flow meter: Single source-single detector. Flow Meas. Instrum. 2019, 69, 101587. [CrossRef]

92. Rad, S.Z.I.; Peyvandi, R.G.; Sadrzadeh, S. Determination of the volume fraction in (water-gasoil-air) multiphase flows using a simple and low-cost technique: Artificial neural networks. Phys. Fluids 2019, 31, 093301. [CrossRef] 